\title{
Inovação Tecnológica no saneamento dentro do contexto da Lei de Licitações $n^{\circ}$ 8666/93
}

\section{Technological Innovation in Sanitation within the context of Bidding Law n. 8666/93}

\section{Marcelo Kenji Miki}

Engenheiro civil e Mestre pela Escola Politécnica da USP, Gerente do Departamento de Execução de Projetos de Pesquisa, Desenvolvimento e Inovação - TXE/SABESP.

Endereço para correspondência: Rua Costa Carvalho, 300 - Piso superior do prédio da prefeitura. Pinheiros - SP - CEP:05429-900 e-mail:mmiki@sabesp.com.br

Data de Entrada: 08/03/2012

Data de aprovação:26/03/2012

\section{RESUMO}

Normalmente o critério de vencimento de uma licitação de materiais e equipamentos se baseia no preço do menor lance, bem como no atendimento às especificaçóes técnicas. O que se questiona neste modelo é a não apropriação de impacto de custos operacionais advindos da superação dos requisitos mínimos especificados. Por um lado a determinação dos requisitos mínimos não pode ser tão restritiva que limite a participação de concorrentes e por outro, não se deveria julgar da mesma maneira uma tecnologia com diferencial superior que traria benefícios na redução dos custos operacionais. Situar-se neste meio termo é o desafio proposto num modelo licitatório que leve em conta este diferencial tecnológico, com o objetivo de induzir a introduçâo de tecnologias inovadoras.

Palavras-Chave: inovação tecnológica, licitação, menor preço.

\section{INTRODUÇÃO}

O tema da inovação vem sendo muito debatido nos meios de comunicação e corre-se o risco de ter o seu sentido desgastado ao longo do tempo. É conveniente remeter a definição proposta pela OECD/Organização para Cooperação e Desenvolvimento Econômico, feita através do Manual de Oslo (2005): uma inovação é a implementação de um produto (bem ou serviço) novo ou significativamente melhorado, ou um processo, ou um novo método de marketing, ou um novo método organizacional nas práticas de negócios, na organização do local de trabalho ou nas relações externas.
Observa-se nesta definição que nem toda inovação deriva necessariamentedasatividadesdePesquisaeDesenvolvimento, pois há as inovações de marketing e organizacional.

Para entender como ocorre a introduçáo de uma inovação tecnológica no setor de saneamento remetemos ao estudo elaborado pela GEOPI/ UNICAMP (2008), que cita como uma das principais características do setor o fato das empresas de saneamento serem tomadoras de inovação vindas de outros setores altamente concentrados (insumos e equipamentos), ou em outras palavras, ser dominada pelo fornecedor de tecnologia.

Entende-se então que grande parte das inovaçóes tecnológicas é introduzida através da compra de materiais e equipamentos. E o processo de aquisição destas tecnologias nas companhias públicas de saneamento é regido pela Lei de Licitaçóes no 8666 (21/06/1993), onde na prática da imensa maioria dos casos, o critério de ganhador é o menor preço do item licitado, bem como atender aos requisitos das especificações técnicas.

No entanto, a principal barreira a ser vencida não se encontra propriamente na interpretação jurídica. Entende-se que o que falta é um maior esclarecimento dos subsídios técnicos que forneçam os elementos necessários para a criação de um novo modelo licitatório.

Em termos de inovação tecnológica, a principal crítica que se faz neste atual modelo licitatório é a não apropriação dos impactos econômicos nos custos operacionais, devido à superaçáo dos requisitos mínimos estabelecidos nas especificaçóes técnicas, como critério 
de julgamento da proposta vencedora. Esta ocorrência de diferenciais tecnológicos entre os fornecedores é o cenário predominante no setor de saneamento e ilustra que a maior parte das inovaçóes é do tipo incremental. Por outro lado, podem ser introduzidas inovações no setor de saneamento, em situaçốes mais raras, através da imposiçáo de requisitos mínimos restritivos e com um número reduzido de fornecedores. A dinâmica do processo neste tipo de situaçáa pode prosseguir com o surgimento de fornecedores com produtos similares.

Faz-se necessária uma inovação nos procedimentos empresariais nas companhias operadoras de saneamento, de modo a cumprir por um lado o que está estabelecido pela lei e por outro lado a induzir a introdução de inovaçóes tecnológicas do tipo incremental.

\section{Menor preço}

A Lei de Licitaçóes no 8666 (21/06/1993) estabelece em seu artigo 15, que as compras, sempre que possível, deverão: "atender ao princípio da padronização, que imponha compatibilidade de especificaçóes técnicas e de desempenho, observadas, quando for o caso, as condiçôes de manutenção, assistência técnica e garantia oferecidas".

Sendo assim, em toda licitaçáo deveria haver uma equalização de desempenho entre os concorrentes.

Já o Artigo 45, parágrafo $1^{\circ}$, inciso I, estabelece a licitação de menor preço: "quando o critério de seleção da proposta mais vantajosa para a Administração determinar que será vencedor o licitante que apresentar a proposta de acordo com as especificaçóes do edital ou convite e ofertar o menor preço".

O que merece ser questionado é a definição de proposta mais vantajosa para a Administração, ou ainda, o menor preço. Quando o menor preço se restringe no preço do lance da aquisição, não se leva em conta o impacto no custo operacional decorrente dos diferenciais tecnológicos que ocorrem quando há a superação dos requisitos mínimos. De forma mais assertiva, podemos dizer que nas situaçôes onde não há compatibilidade de especificaçóes técnicas e de desempenho, não está se cumprindo o estabelecido na Lei de Licitaçóes.

Um processo licitatório deveria levar em conta os chamados CAPEX e OPEX, que seriam respectivamente:
- CAPEX (Capital Expenditure): o montante de dinheiro despendido na aquisição (ou introdução de melhorias) de bens de capital de uma determinada empresa;

- OPEX (Operational Expenditure): significa o capital utilizado para manter ou melhorar os bens físicos de uma empresa, tais como equipamentos, propriedades e imóveis.

O menor preço deveria avaliar o valor presente composto do preço do objeto ofertado e os impactos dos custos operacionais devido aos diferenciais tecnológicos em relação a uma referência, para uma determinada taxa de desconto e um determinado horizonte de tempo, conforme ilustrado na Figura 1.

Dentro do contexto regido pela introdução de novos instrumentos regulatórios estabelecido pela Agência Reguladora de Saneamento e Energia do Estado de São Paulo, ARSESP, pode-se recomendar para os estudos de viabilidade econômica no Estado para a taxa de desconto o valor do WACC/Weighted Average Cost of Capital, Custo Médio Ponderado de Capital, cujo valor atual é de 8,06\% ao ano.

Figura 1: Fluxo para determinaçâo do Valor presente

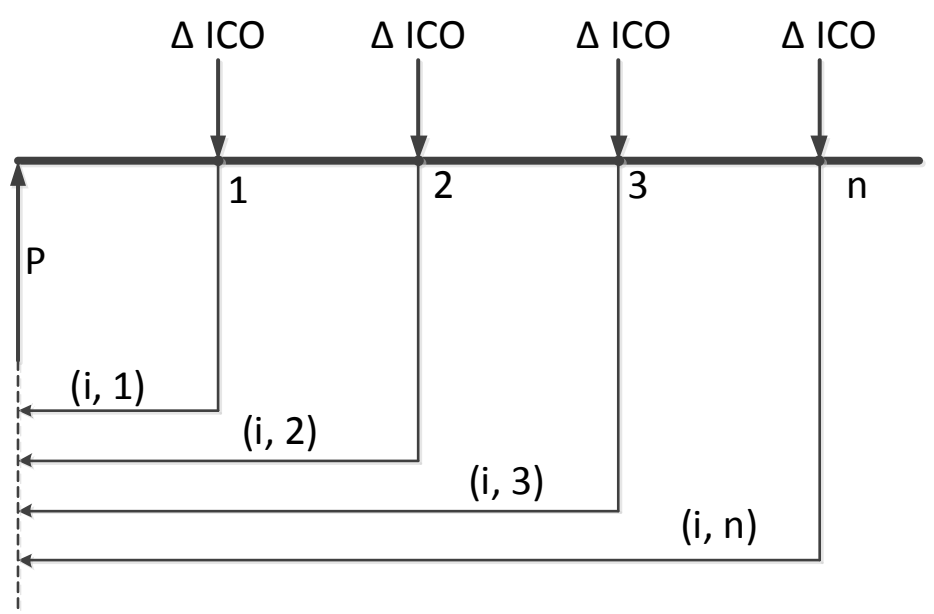

Onde

P: oferta do preço do objeto licitado;

i: taxa de desconto;

n: número de períodos considerados (horizonte de tempo)

$\triangle$ ICO: diferencial de custos operacionais

em relação a uma referência 


\section{Fundamentos técnicos}

Para se avaliar o impacto no custo operacional devido aos diferenciais tecnológicos devem ser levantadas informações que subsidiem a modelagem, de modo a gerar os impactos econômicos. É justamente aí que reside o desafio num novo modelo licitatório, pois há a necessidade de um conjunto de conhecimento técnico para embasar a sustentação teórica deste modelo.

Estabelecer fatores de desempenho depende primariamente da escolha de parâmetros técnicos facilmente mensuráveis e que não recaiam em subjetividade. Podem ser escolhidos mais de um fator de desempenho operacional que impactam os custos operacionais. E para que sejam calculados os impactos dos custos operacionais, necessita-se saber os valores dos insumos envolvidos.

\section{Fator de produtividade}

No caso de equipamentos, um dos primeiros itens a serem equalizados refere-se à própria capacidade de trabalho. Na grande maioria dos casos de licitação de equipamentos, estabelece-se uma capacidade mínima de trabalho. Salvo raras exceçóes, como em bombas com rotores especialmente montados para determinada condição operacional, é possível atender de forma pontual uma determinada capacidade de trabalho.

Para a outra grande maioria dos casos, deve-se estabelecer a condiçáo operacional de trabalho de modo a se encontrar a produtividade de determinado equipamento e sua respectiva carga horária de trabalho realizada num determinado período.

No caso de bombas para estaçôes elevatórias de água ou esgoto, deve-se ter em primeiro lugar a chamada curva do sistema, que é um gráfico que relaciona a vazão com a perda de carga. Podemos citar aí uma pequena barreira técnica, pois comumente o requisito técnico estabelecido nas licitações de bombas limita-se muitas vezes ao desnível geométrico de altura e a vazão necessária. A razão para esta simplificação é muitas vezes a falta de informações técnicas obtidas do cadastro técnico, que deveria ter

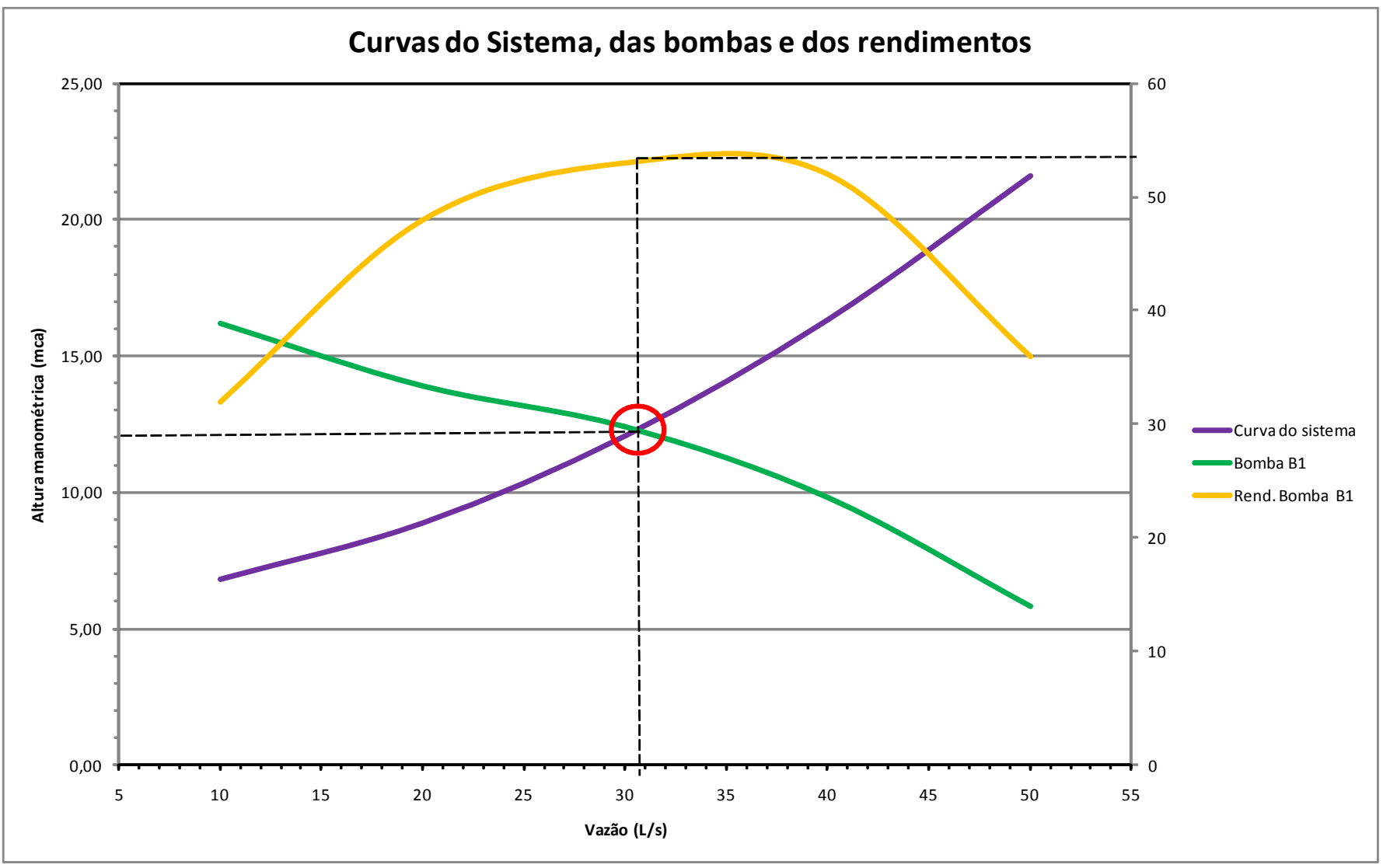

Figura 2: Exemplo de curvas do sistema, bomba e rendimento 
registrado o projeto "as built" com informaçóes como diâmetro da tubulação, extensão da linha de recalque, tipo do material, quantidade de singularidades como válvulas, curvas e registros, etc. Somente com estas informações técnicas é que se pode levantar a curva do sistema. Em segundo lugar deve ser fornecida a curva da bomba por cada fabricante participante da licitação, que relaciona a vazão processada com sua respectiva perda de carga.

A sobreposição das curvas do sistema e da bomba resulta na intersecçáo de um ponto, que seria o ponto operacional da bomba naquela condição de trabalho.

Conforme ilustrado na Figura 2, para cada ponto de trabalho da bomba, haverá uma determinada vazão e uma quantidade de horas correspondentes para o bombeamento de um determinado volume estabelecido. Desta forma é realizada a parametrização referente à capacidade de trabalho do equipamento, ou ainda, $\underline{\text { o }}$ fator de produtividade.

Um aspecto relevante do fator de produtividade que merece ser mencionado é a sua amarração com os fatores de desempenho, pois estes fatores estão interrelacionados.

\section{Fatores de Desempenho Operacional}

Em termos prioritários, pode-se destacar o fator de desempenho operacional relacionado à eficiência energética, já que o gasto com energia elétrica representa o segundo maior item de custo operacional nas companhias saneamento no Brasil, sendo superado apenas pelas despesas com pessoal (salários + encargos). Num contexto mais amplo, pode-se citar que o bombeamento demanda aproximadamente $20 \%$ da energia elétrica gerada no mundo e que de 20 a $50 \%$ da energia elétrica é consumida somente na etapa de bombeamento em determinados segmentos da indústria, conforme o HYDRAULIC INSTITUTE (2001).

No caso de conjunto moto bomba, feita a parametrização do fator de produtividade, através da obtenção do ponto de operação, encontra-se a respectiva eficiência energética do conjunto moto bomba na curva de eficiência.

O passo final é determinação da potência consumida do conjunto moto bomba e conseqüentemente a energia específica para o bombeamento $\left(\mathrm{kW} / \mathrm{m}^{3}\right)$. Para cada bomba haverá uma capacidade de trabalho e um determinado número de horas trabalhadas, podendose calcular finalmente a energia elétrica consumida no período considerado. A inspeção, normalmente realizada para o recebimento de equipamentos, poderia checar não só o atendimento do requisito mínimo, como também o diferencial de superação de consumo de energia elétrica e assim confrontar com a informação de desempenho operacional utilizada no critério de julgamento.

\section{Horizonte de tempo do estudo}

O estabelecimento do horizonte de estudo deve tomar certas precauçóes de forma a não provocar distorçóes no critério de julgamento.

Uma forma de fazer estes estudos técnico-econômicos é adotar como parâmetro de avaliaçáo o horizonte de tempo igual à vida útil. De acordo com o Hydraulic Institute (2001) um conjunto moto bomba tem uma vida útil entre 15 a 20 anos. Este longo horizonte de tempo pode levar a distorções na avaliação final, caso não haja outras informaçôes relevantes, como os custos de manutenção corretiva e preventiva que irão ocorrer ao longo da vida útil. Como este exercício de prever estes custos de manutenção é algo extremamente complexo do ponto de vista técnico, devido a uma enorme quantidade de variáveis, é preferível eliminar esta variável através de outra abordagem.

Entendemos que o período de tempo a ser adotado é justamente o intervalo onde não irão ocorrer intervenções significativas em termos de manutenção e troca dos componentes mais críticos, como por exemplo, o rotor da bomba ou a rosca transportadora de lodo numa centrífuga. Assim a adoção de um horizonte de tempo depende muito do conhecimento técnico da área e deve, caso a caso, embasar e justificar o período de tempo.

Por exemplo, no caso de conjunto moto bomba deve-se levar em conta a altura manométrica, a existência ou não de caixa de areia e gradeamento, a abrasividade do esgoto coletado no local, etc e com base nos registros históricos e nas diferentes tipologias estabelecer um período de tempo isento de intervençóes de manutenção mais profundas. Fica ilustrado mais uma vez outra barreira técnica que pode ocorrer, devido à falta de uma sistematização de informaçóes.

E para assegurar o estabelecimento deste horizonte 


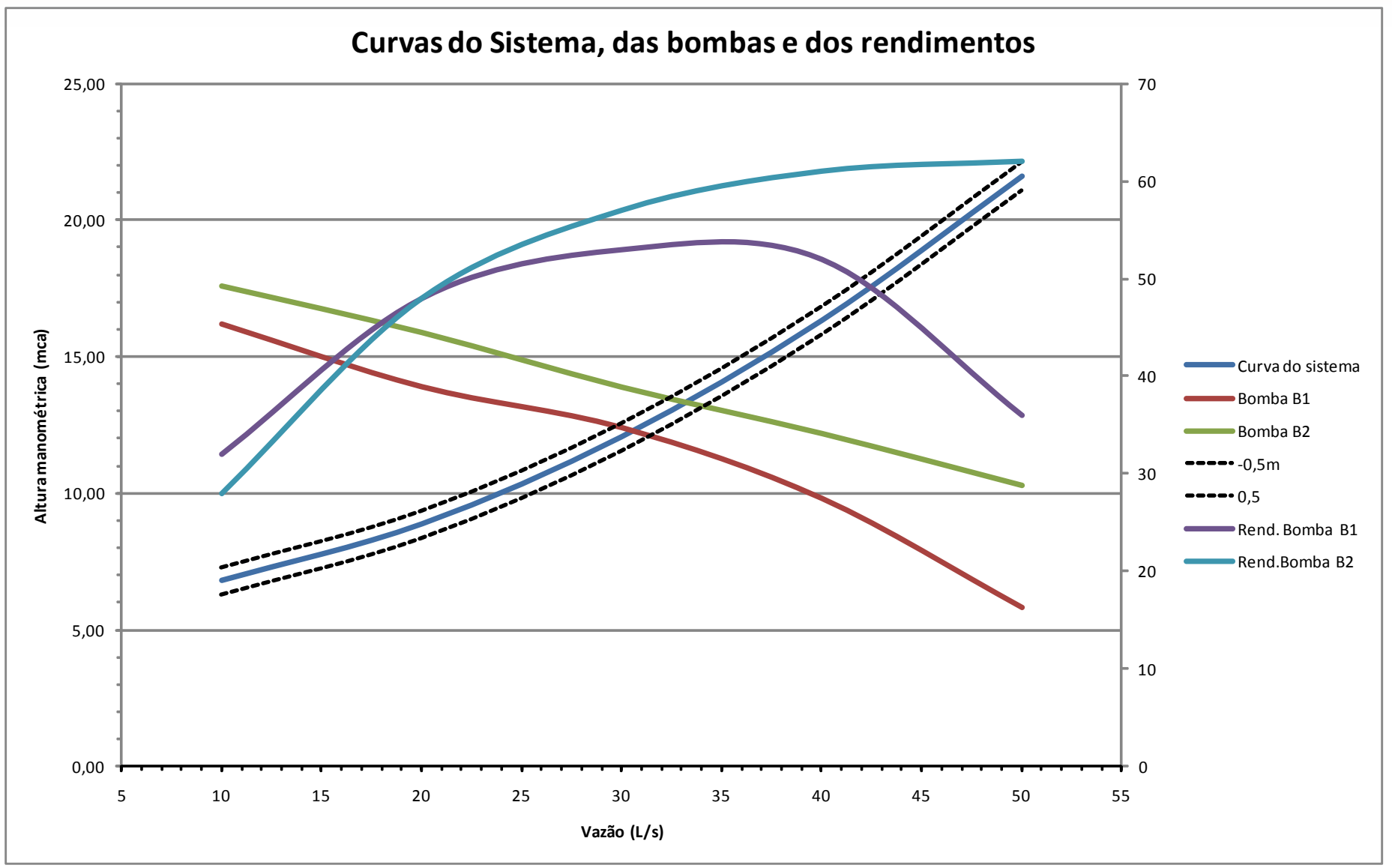

Figura 3: Curvas do Sistema, bombas e rendimentos para determinação do fator de produtividade e de desempenho operacional de um exemplo prático

de tempo podem ser exigidos requisitos técnicos relacionados aos aspectos construtivos do equipamento, como por exemplo, a resistência mecânica do material de fabricação da carcaça da bomba. Este tipo de abordagem permite um maior controle sobre a variabilidade dos parâmetros relacionados à vida útil dos equipamentos, bem como da perda progressiva do desempenho ao longo do tempo.

\section{RESULTADOS}

\section{Impactos nos custos operacionais}

Para ilustrar os impactos nos custos operacionais escolheu-se uma licitação recentemente realizada em Registro de um conjunto moto bomba com potência máxima ao redor de $10 \mathrm{CV}$ e aplicaramse os procedimentos de determinação do fator de produtividade e de desempenho operacional, descritos anteriormente.
Tabela 1: Obtenção dos parâmetros de produtividade e de desempenho para um caso de Registro

\begin{tabular}{|c|c|c|}
\hline \multirow{2}{*}{ Parâmetros } & \multicolumn{2}{|c|}{ Bomba } \\
\cline { 2 - 3 } & B1 & B2 \\
\hline$\eta($ motor+bomba) & 0,53 & 0,6 \\
\hline Vazão $(\mathrm{L} / \mathrm{s})$ & 30,5 & 35,2 \\
\hline Hman $(\mathrm{mca})$ & 11,9 & 13 \\
\hline Tempo de operação anual $(\mathrm{h})$ & 4.308 & 3.733 \\
\hline Custo de energia $(\mathrm{R} \$ / \mathrm{kW} . \mathrm{h})$ & \multicolumn{2}{|c|}{0,278} \\
\hline Peso específico: $\gamma\left(\mathrm{kg} / \mathrm{m}^{3}\right)$ & \multicolumn{2}{|c|}{1.000} \\
\hline Vazão média $(\mathrm{L} / \mathrm{s})$ & \multicolumn{2}{|c|}{15} \\
\hline Taxa de desconto & \multicolumn{2}{|c|}{$8,06 \%$} \\
\hline
\end{tabular}

Os resultados da obtenção dos parâmetros de produtividade e de desempenho estáo listados na Tabela 1, obtidos a partir do gráfico apresentado na Figura 3. 


\section{Procedimentos operacionais e empreendimentos}

E de posse destes parâmetros com o custo dos insumos podemos calcular gastos de operação de cada fornecedor e conseqüentemente calcular os impactos de custo operacional entre os fornecedores devido aos diferenciais tecnológicos, conforme os dados apresentados nas tabelas 2 e 3 .

Tabela 2: Gastos operacionais anuais de energia elétrica para 2 casos de bomba

\begin{tabular}{|c|c|c|c|}
\hline Bomba & $\begin{array}{c}\text { Potência } \\
\text { CMB (CV) }\end{array}$ & $\begin{array}{c}\text { Gasto anual } \\
\text { de energia } \\
\text { (R\$/ano) }\end{array}$ & $\begin{array}{c}\text { Energia } \\
\text { específica } \\
\left(\mathrm{W} / \mathrm{m}^{3}\right)\end{array}$ \\
\hline B1 & 9,13 & 8048,74 & 61,20 \\
\hline B2 & 10,17 & 7766,92 & 59,06 \\
\hline
\end{tabular}

Linha de base: referente ao gasto de energia elétrica mais alto referente a bomba 1

CE1: custo de energia elétrica referente a bomba $1=\mathrm{R} \$$ $8048,74 /$ ano

CE2: custo de energia elétrica referente a bomba $2=\mathrm{R} \$$ $7766,92 /$ ano
EE21, Economia de Custo no consumo de energia elétrica, $\mathrm{CE} 1-\mathrm{CE} 2=\mathrm{R} \$ 8048,74-\mathrm{R} \$ 7766,92=\mathrm{R} \$$ $281,82 /$ ano

\section{Valor Presente}

Para o nosso caso, enquanto o valor presente para o fornecedor B1 seria igual ao preço unitário do lance a ser proposto, o valor presente para o fornecedor B2 será o preço do lance descontado do impacto operacional econômico parametrizado devido ao diferencial tecnológico (para um horizonte de 5 anos).

Valor Presente $=$ Preço do Lance de B2 $-\mathrm{R} \$ 1788,71$

A estimativa de preço de um conjunto moto bomba com estas características está na ordem de 13 mil reais, assim a ordem de grandeza de desconto para o fornecedor com melhor desempenho operacional seria da ordem de $14 \%$ num horizonte de período 5 anos. Para um horizonte de 20 anos correspondente a vida útil do equipamento, o desconto seria na mesma ordem de grandeza do valor do equipamento.

Tabela 3: Impactos positivos de custos operacionais de energia elétrica trazidos a valor presente, conforme período

\begin{tabular}{|c|c|c|c|}
\hline Anos & $\begin{array}{c}\text { Impacto no custo operacional } \\
\text { anual de B1 (R\$/ano) }\end{array}$ & $\begin{array}{c}\text { Impacto positivo no } \\
\text { custo operacional anual } \\
\text { de B2 (R\$/ano) }\end{array}$ & $\begin{array}{c}\text { Impacto positivo no } \\
\text { custo operacional } \\
\text { acumulado de B2 (R\$) }\end{array}$ \\
\hline 1 & $\mathrm{R} \$ 0,00$ & $\mathrm{R} \$ 304,53$ & $\mathrm{R} \$ 304,53$ \\
\hline 2 & $\mathrm{R} \$ 0,00$ & $\mathrm{R} \$ 329,08$ & $\mathrm{R} \$ 633,61$ \\
\hline 3 & $\mathrm{R} \$ 0,00$ & $\mathrm{R} \$ 355,60$ & $\mathrm{R} \$ 989,21$ \\
\hline 4 & $\mathrm{R} \$ 0,00$ & $\mathrm{R} \$ 384,26$ & $\mathrm{R} \$ 1737,48$ \\
\hline 5 & $\mathrm{R} \$ 0,00$ & $\mathrm{R} \$ 415,24$ & $\mathrm{R} \$ 2.237,42$ \\
\hline 6 & $\mathrm{R} \$ 0,00$ & $\mathrm{R} \$ 448,70$ & $\mathrm{R} \$ 2.722,29$ \\
\hline 7 & $\mathrm{R} \$ 0,00$ & $\mathrm{R} \$ 484,87$ & $\mathrm{R} \$ 3.246,23$ \\
\hline 8 & $\mathrm{R} \$ 0,00$ & $\mathrm{R} \$ 523,95$ & $\mathrm{R} \$ 3.812,41$ \\
\hline 9 & $\mathrm{R} \$ 0,00$ & $\mathrm{R} \$ 566,18$ & $\mathrm{R} \$ 4.424,23$ \\
\hline 10 & $\mathrm{R} \$ 0,00$ & $\mathrm{R} \$ 611,81$ & $\mathrm{R} \$ 5.085,35$ \\
\hline 11 & $\mathrm{R} \$ 0,00$ & $\mathrm{R} \$ 661,13$ & $\mathrm{R} \$ 5.799,77$ \\
\hline 12 & $\mathrm{R} \$ 0,00$ & $\mathrm{R} \$ 714,41$ & $\mathrm{R} \$ 6.571,76$ \\
\hline 13 & $\mathrm{R} \$ 0,00$ & $\mathrm{R} \$ 771,99$ & $\mathrm{R} \$ 7.405,98$ \\
\hline 14 & $\mathrm{R} \$ 0,00$ & $\mathrm{R} \$ 834,22$ & $\mathrm{R} \$ 8.307,43$ \\
\hline 15 & $\mathrm{R} \$ 0,00$ & $\mathrm{R} \$ 901,45$ & $\mathrm{R} \$ 9.281,55$ \\
\hline 16 & $\mathrm{R} \$ 0,00$ & $\mathrm{R} \$ 974,11$ & $\mathrm{R} \$ 10.334,17$ \\
\hline 17 & $\mathrm{R} \$ 0,00$ & $\mathrm{R} \$ 1.052,63$ & $\mathrm{R} \$ 11.471,64$ \\
\hline 18 & $\mathrm{R} \$ 0,00$ & $\mathrm{R} \$ 1.137,47$ & $\mathrm{R} \$ 12.700,79$ \\
\hline 19 & $\mathrm{R} \$ 0,00$ & $\mathrm{R} \$ 1.229,15$ & $\mathrm{R} \$ 14.029,00$ \\
\hline 20 & $\mathrm{R} \$ 0,00$ & $\mathrm{R} \$ 1.328,22$ & \\
\hline
\end{tabular}




\section{DISCUSSÓES}

Para que um modelo se sustente necessita-se submetêlo a diversas provas argumentativas para que sobreviva. Ao longo do texto procuramos ilustrar apenas com alguns exemplos.

Há ainda outras questôes que merecem uma reflexão. Pode-se questionar como seria o processo de obtenção dos dados de desempenho operacional a serem alimentado num processo licitatório, já que isto implica numa vantagem para vencimento da licitação. Este importante questionamento poderia ser respondido de duas formas. A primeira alternativa seria uma auto-declaração a priori, em que o fornecedor poderia informar os parâmetros de produtividade e de desempenho operacional. O prosseguimento deste processo se daria na etapa de inspeção do equipamento e checar em bancada se os valores declarados corresponderiam aos valores medidos. Caso houvesse uma discrepância desfavorável, aplicar-se-iam as devidas multas contratuais. Espera-se este procedimento coíba a declaração de valores muito ousados, pois se de um lado permite o vencimento da licitação, por outro lado permite a punição caso não se alcance os valores de desempenho declarados. A segunda alternativa poderia ser a realizaçáo de testes com todos os fornecedores e avaliados nas mesmas condiçóes. Esta alternativa apresenta uma logística mais complexa e envolveria custos de mobilização, desmobilização e do próprio levantamento de informações.

\section{CONCLUSÁO}

Caso haja uma superação nos requisitos mínimos de desempenho operacional estabelecidos nas especificações técnicas, deve-se contabilizar este impacto de custo operacional no processo licitatório de forma a se avaliar a proposta mais vantajosa. Cabe lembrar que muitas vezes as vantagens técnicas entre diferentes fornecedores ocorrem no nível incremental e não na forma disruptiva.

O menor preço não se limita ao valor do lance de um objeto, mas deve incorporar os devidos impactos nos custos operacionais advindos dos diferenciais tecnológicos. Algumas companhias de saneamento já começaram a lançar editais que incorporam os custos dos impactos operacionais devido a diferenciais tecnológicos no julgamento das propostas, podendo ser citados a CAESB, CORSAN, CAERN.
$\mathrm{O}$ estabelecimento dos fatores de produtividade e de desempenho operacional depende uma investigação profunda de informaçóes, de forma a fornecer critérios de avaliação da proposta mais vantajosa.

Este tipo de avaliação da busca da proposta mais vantajosa é algo que deve ser comum tanto em empresas públicas como em privadas. A diferença numa empresa pública é a necessidade de se ter transparência ao longo do processo de avaliação à vista de todos os atores, diferente num empresa privada em que a negociação pode ser feita às portas fechadas e em diferentes momentos.

Por outro lado uma tecnologia superior pode não trazer benefícios de custos operacionais a longo prazo, caso o seu preço seja abusivo.

O modelo licitatório proposto busca avaliar a proposta mais vantajosa de forma mais ampla do que a atualmente praticada.

De forma esquemática, pode-se resumir o modelo na seguinte equação:

Menor preço $=$ Menor Custo Total $=$ Preço Unitário + Impacto de Custo Operacional trazido a Valor Presente

Sendo Preço Unitário o valor a ser recebido efetivamente pelo fornecedor vencedor da licitação.

A devida contabilização dos benefícios econômicos decorrentes dos diferenciais tecnológicos num processo licitatório certamente irá induzir os fornecedores a que busquem ofertar continuamente equipamentos e materiais com diferencias tecnológicos, derivados de esforços de pesquisa, desenvolvimento e inovação.

\section{RECOMENDAÇÓES}

Recomenda-se utilizar e aprimorar este modelo de licitação nas diversas empresas operadoras de saneamento de modo a induzir a introdução de inovaçóes tecnológicas incrementais. Entendemos que este modelo é sustentável onde há a preocupação de se monitorar efetivamente a questão de eficiência operacional nas diversas vertentes de uma companhia de saneamento. 


\title{
Procedimentos operacionais e empreendimentos
}

\section{REFERÊNCIAS BIBLIOGRÁFICAS}

1. FINEP, Manual de OSLO, Diretrizes para coleta e interpretaçâo de dados sobre inovação, $3^{a}$ edição, OECD, (2005).

2. HYDRAULIC INSTITUTE, EUROPUMP; US DEPARTMENT OF ENERGY'S OFFICE OF
INDUSTRIAL TECHNOLOGIES (OIT). Pump Life Cycle Costs: A guide to LCC analysis for pumping systems (2001)

3. GEOPI/UNICAMP, Produto 1, Radiografia da Inovação; Concepção, Desenvolvimento e Implantação de Modelo de Gestão em Tecnologia e Inovação na SABESP, OUT 2008.

\section{O site da Revista DAE está repleto de novidades}

\author{
Assine gratuitamente o boletim \\ eletrônico, é só se cadastrar!
}

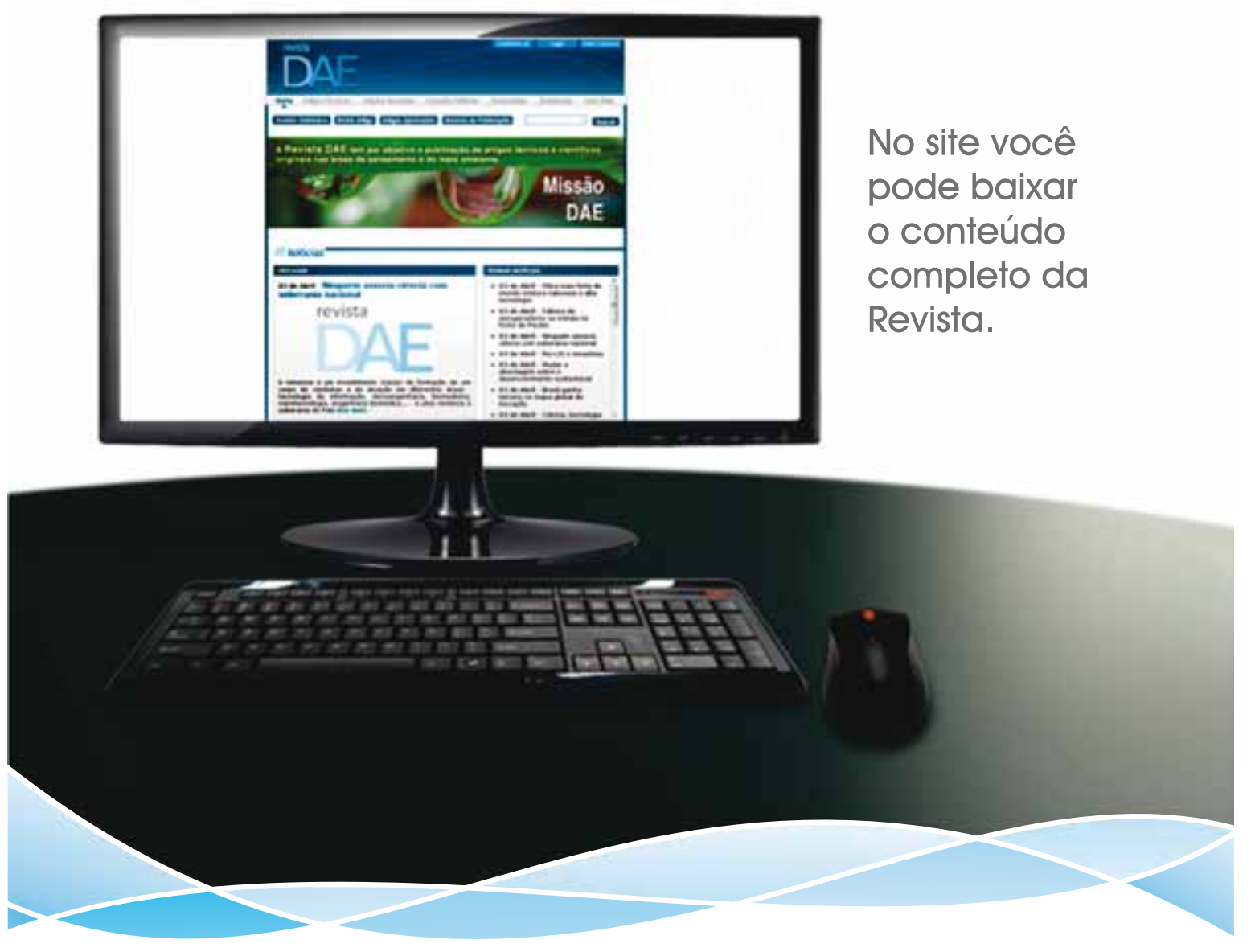

